\title{
Evaluating types of students' interactions in a wiki-based collaborative learning project
}

\author{
Maria Prokofieva \\ Victoria University, Australia
}

\begin{abstract}
Wiki technology has been promoted as a collaborative software platform. This study investigates interactions that occur in a wiki-based collaborative learning project. The study draws on interaction literature and investigates the types of interactions with which students are engaged in wiki-based group projects, clusters that reflect online interaction patterns and factors that affect students' interaction. The study employs a quantitative approach (principal component analysis, cluster analysis and Kruskal-Wallis test) and a qualitative approach (interviews). The results show that students' interactions online were of two types, student-content and student-student, with student-content interaction being dominant. An increase in online interaction was driven mainly by an increase in student-content interaction, while student-student interaction increased to a certain level and then stayed the same. The study also discusses factors that influenced both types of interaction and suggests guidelines on how student-student interaction can be encouraged.
\end{abstract}

\section{Introduction}

The development of wikis has changed the internet community by providing an easily editable virtual space for collaborative knowledge creation (Zorko, 2009). It achieves this through transforming one's own knowledge into a shared digital artefact (Lee \& Tsai, 2011). Such flexibility is reflected in the functionalities that allow users to represent data in a freer manner than existing asynchronous learning tools such as discussion boards (Choy \& Ng, 2007). Equipped with this technology, users can participate actively in the creation of the content itself and share it with others (O'Reilly, 2007). Fascinated with such a potential for collaboration, educators have started using wikis in the classroom (Green \& Hannon, 2007; Redecker, 2009; Kear, Woodthorpe, Robertson, \& Hutchison, 2010). Educators have discussed the practical application of wikis in a wide range of disciplines, including computer science courses (Bower, Woo, Roberts, \& Watters, 2006), language learning (Richardson, 2006), health science courses (Snodgrass, 2011) and others.

Wiki projects have started to replace face-to-face based group activities (e.g., oral group presentation, or more commonly, a group written assignment). However, the results of studies on wiki effectiveness are ambiguous. Some researchers indicate that wikis support collaborative learning (Elgort, Smith, \& Toland, 2008; Snodgrass, 2011), reduce free riding in group activities and encourage a more equal contribution by group members (Zorko, 2009). In contrast, other researchers argue that wiki collaboration is not effective (Judd, Kennedy, \& Cropper, 2010; Naismith, Lee, \& Pilkington, 2011), that students may tend to only read the information to which they contributed or wish to take individual credit for their own work in a group (Wheeler, Yeomans, \& Wheeler, 2008; Snodgrass, 2011), and that students may experience confusion and uncertainty about online tasks (Snodgrass, 2011). This ambiguity of the effectiveness of wiki collaboration is the motivation for the study, while the interaction process is the focus of the present research. By analysing interactions in a collaborative project, the study investigates the patterns in interactions and factors that contribute to the loss of collaborative opportunities.

While there exist approaches to evaluate individual contributions of students in a collaborative learning project (Trentin, 2009; Judd et al., 2010), the literature on evaluation of interactions has not yet been fully dealt with as highlighted in a number of studies (Gredler, 2005; Trentin, 2009; Moskaliuk, Kimmerle, \& Cress, 2012). The objective of this paper is to address this lack and extend prior research by investigating interactions in collaborative projects in a blended learning environment. This paper contributes to prior research by investigating the types of interactions that students are engaged in wiki projects, identifying differences between clusters of students and extending factors that affect online collaboration with a view of offline interaction. The paper suggests guidelines to encourage online/offline interactions and evaluate interactions in collaborative projects. These guidelines can be utilised in teaching and learning settings to 
improve instructional design of a growing number of educational wiki projects, thereby enhancing the quality of collaboration and increasing the effectiveness of such collaborative projects.

\section{Prior studies}

Wikis are websites developed interactively by a community of users using simple online tools (Judd et al., 2010). The essence of a wiki is collaboration, characterized by participants who share a common goal, are at a similar level and can perform the same actions while working together (Oliveira, Tinoca, \& Pereira, 2011). Collaboration allows integration of an individual student's work into a simple and homogeneous knowledge repository that is available to all participants of a learning group (Lundin, 2008).

Collaboration can be easily confused with cooperation. While collaboration includes a continuous attempt to develop and maintain a shared meaning of a task, cooperation involves the division of work when each participant is responsible for a part of the task (Roschelle \& Teasley, 1995). Applied to a learning situation, cooperative learning takes place at the individual level with the group product being a collection of individual results. By comparison, collaborative learning is viewed as the collaborative construction of knowledge. Activities that individuals undertake in collaborative learning are not individual-learning activities, but are group interactions, e.g., negotiation and sharing (Stahl, Koschmann, \& Suthers, 2006). Learning that occurs through collaboration is believed to encourage deeper engagement with the learning content through situated action and interaction (Naismith et al., 2011). The quality of the collaborative learning is directly affected by the quality of the collaborative process that includes individual contribution levels and interactions within the group (Trentin, 2009).

Interaction has always been discussed as a crucial element in teaching and learning (Anderson, 2008). There exist many definitions of interaction (Carlson \& Reepman, 1999; Hirumi, 2002; Sims, 2003; Yun, 2005). For the purposes of this study, interactions are defined as "reciprocal events that require at least two objects and two actions. Interactions occur when the objects and events mutually influence one another" (Anderson, 2008, p.55). This definition extends the concept of interaction from two-way contact with another person (or persons) to a more abstract and technical level that encompasses the learner's engagement with the content, technology, other learners and the instructor.

Interaction has long been regarded as the vital factor in successful technology-mediated education. Wagner (2005) argues that the perceived quality of a learning experience is directly proportional to, and positively correlated with, the degree to which that experience is seen as interactive. To increase the effect of pedagogical practices, the technology-mediated learning design needs to maximise the benefit of interaction. Yun (2005) provides evidence that instructional strategies which incorporate various types of interactions can be the key to teaching a high-quality online course that engages students. In her later work, Wagner (2006) suggests that interaction should be viewed less as a theoretical construct and more as a variable that needed to be exploited, accommodated, leveraged or managed when developing blended learning designs.

Existing literature provides several taxonomies of educational interaction. One of the mostly widely used is based on the actors participating in the interactions, student-content, student-instructor, and studentstudent (Moore, 1989). In this taxonomy, interaction is viewed as transaction in which learner's collaboration is reflected as the degree and quality of engagement with others (Donnelly, 2010).

The student-content interaction is "'internal didactic conversation' when learners 'talk to themselves' about the information and ideas they encounter" (Moore, 1989, p. 2). The student-student interaction occurs as learners share knowledge with their peers and receive feedback. The student-instructor interaction is interaction between the learner and the expert who prepared the subject material, or some other expert acting as instructor.

In traditional classroom settings, these three types of interactions may not be meaningfully correlated (Ting, 2013), while in technology-mediated learning, these types of interactions are of primary importance. Further development of online collaboration software, including the introduction of wikibased learning projects, puts educational interactions at the core for all levels of engagement and requires a more comprehensive approach to analysis of interactions in a collaborative project. 
Applying Moore's taxonomy (1989) and Anderson's approach (2008) to interactions in a wiki-based collaborative project the following research questions (RQ) are established:

RQ1: What types of interactions are students engaged online in a wiki-based collaborative project? RQ2: Can any meaningful clusters of students be discovered based on their online interaction pattern? RQ3: What factors influence interaction in wiki-based collaborative activities?

\section{Course context}

This research used a case study approach with a mixed methodology. According to Creswell (1998), this approach allows for the collection of data from multiple sources thereby leading to a deeper understanding of a topic. The project was approved by the University's Human Research Ethics Office. The study was conducted on a postgraduate-level accounting unit taught at a metropolitan Australian university in 2010-2011. The unit is offered as an elective for Master's programs and does not have prerequisites. The unit selection was based on the following criteria:

(a) throughout one semester students were exposed to different types of collaborative projects/tasks. Exposure to online/offline collaborative activities was shown to stimulate interactions (Michinov \& Michinov, 2008);

(b) at least one of the collaborative group projects was based on a wiki; and

(c) the wiki platforms used allowed the collection of web statistics regarding online usage.

During the semester students were asked to undertake three separate collaborative projects, including a wiki-based project. They were asked to complete the activities in groups of three. Based on prior studies on collaborative learning by Kagan (1989) and Johnson, Johnson, and Holubec (1984), a heterogeneous approach to group formation was adopted. Evaluation of the existing group activities showed that their design was guided by the literature on collaborative learning. Following Bryant and Albring (2006), the group assignments were sufficiently complex and unstructured in nature to require interdependency of group members and hence encourage group collaboration. The main focus of this study is the online project, in which students were asked to use a wiki to create a knowledge database on financial analysis. This task was subdivided into mini-tasks that were released to students each week throughout the semester. During the first 20 minutes of every tutorial, students were asked to work in their groups. Each student group was given a task to collaborate and write an article (no more than 500 words) on a specific topic related to the material covered during the lecture, e.g., Industry analysis, Valuation, Acquisitions, etc. The article was presented as a separate wiki page or a set of linked pages where each student wrote their contributions (Figure 1).

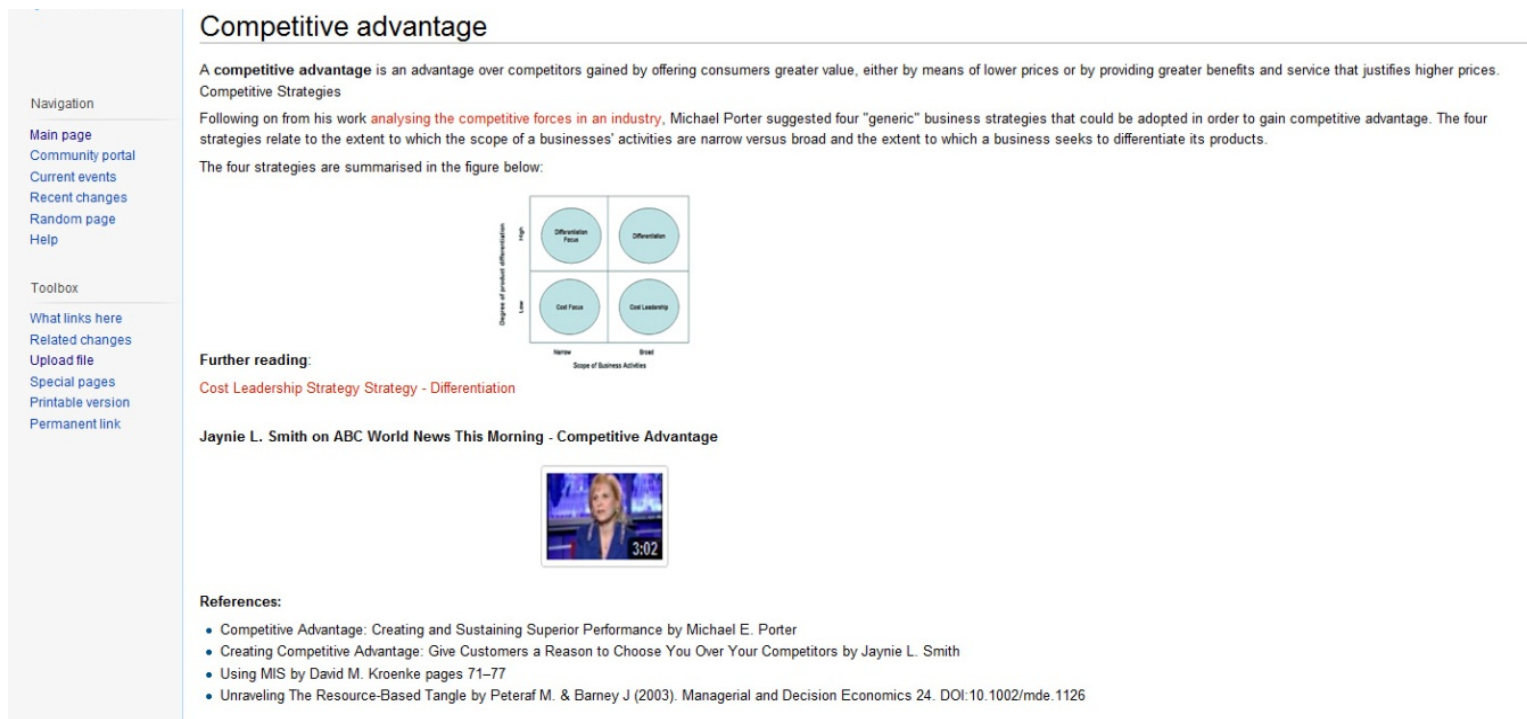

Figure 1. Financial analysis wiki page. 
Following Snodgrass (2011), wiki-based tasks were linked with specific learning objectives and assessment to stimulate online participation. Mini-tasks were based on weekly class extension question tasks (Choy \& Ng, 2007) as task authenticity was assumed to be one of the main factors encouraging student contributions and promoting a more favourable learning experience. Students were provided with a list of study materials as a starting point to approach the set of mini-tasks. Following Trentin (2009), students were instructed to discuss each mini-task within a group, develop a shared meaning of a task and keep collaborating as they moved through the task. For each mini-task, groups were provided with an option to share a wiki page. Alternatively, students were allowed to work on individual pages and link them later. Each group was assigned a separate topic. However, students were encouraged to browse pages/sections created by other students, comment on the content and provide suggestions on how it could be improved. To ensure participation, feedback that added value to individual topics were counted towards assessment. As they progressed through mini-tasks, students were also expected to develop a structure of links to/from pages conceptually linked to their own. The aim of this approach was to increase interaction between users (Trentin, 2009). The role of the instructor was to engage with student groups, discuss design and implementation choices and provide suggestions on the collaborative aspects of mini-tasks.

In the first tutorial, each student was given a user account that included rights to create new pages, to link pages with pages created by other users, to edit, to leave comments and to upload images and video files. The students were also provided with introductory training that included an overview of group work, and guidelines for using the wiki platform. They were also given an opportunity to familiarise themselves with the wiki protocol. Prior research by Vratulisa and Dobsona (2008) indicates that these activities facilitate working in an online/blended environment. The students were also warned that any changes they made to their wiki would be recorded by the system and would be monitored in terms of general use, content quality, frequency of visits and "netiquette".

\section{Research design and data collection}

To address the research questions, a two-stage research design was used. The first stage employed data mining techniques to obtain information about students' online interactions, while the second stage provided insights into the offline as well as online component of the wiki project.

The first stage involved the collection of data from server logs. All wikis used were installed on a private server that allowed the logging of all activities during the course. The server logs included records of all online interactions occurring during the course, such as viewing, adding, updating, deleting, etc. The logs were used to analyse online interactions and address RQ1 and RQ2. The logs were obtained by performing SQL requests to each of the wiki databases on the server. Each row in the log provided information on the user, action and time. The data were cross-checked with usage patterns determined by Google Analytics. The log was pre-processed to remove all irrelevant, irregular and missing data. Following Trentin (2009) and Snodgrass (2011), further analysis used threshold for quality of contributions. The acceptable contribution was defined as an addition that includes at least one complete meaningful sentence. Only contributions of adequate quality were included in the count. The data on user actions were analysed further to identify a set of interactions that users undertook during the course. The identified set of interactions was limited by the design of the wiki database tables used for version control. Logging on/off was ignored for the purposes of our study, since the wiki engine allowed autologging off when a user was idle for an extended period of time. Logging off was not recorded when a user browsed the wiki, making it difficult to match logging in and logging off. The identified set of interactions was cross-checked with prior literature on wiki scripting and online collaboration (Oliveira et al., 2011; Moskaliuk et al., 2012; Wichmann \& Rummel, 2013). A description of the variables extracted from the logs is provided in Appendix A.

To investigate students' interactions in the wiki, the study employed descriptive statistical analysis, principal component analysis with orthogonal rotation (varimax), cluster analysis using the K-means algorithm and Kruskal-Wallis test.

In the second stage of the research, the students were invited to participate in semi-structured interviews to comment on their online/offline performance and collaboration. It was intended that the qualitative data from interviews would triangulate and extend conclusions arising from the analysis of the quantitative 
data from server logs and would address RQ2 and RQ3. All interviews were conducted after academic results were finalised. This was done to avoid a perception that not participating in the interview could negatively affect students' academic progress. Content analysis was employed to analyse the interview data.

\section{Results and discussion}

\section{Descriptive statistics}

The study used 59,136 web statistics records attributable to 83 students enrolled in the unit of study. The number includes only those students who were enrolled in this course from week 1 and were able to complete the course. This number does not include the total of four students who withdrew from the unit for semester 2, 2010 and 2011. Further analysis showed that the withdrawals were caused by timetable clashes.

The distribution of students in the sample by place of residence showed that $58 \%$ were international students while local students made up $42 \%$ of the sample. All international students were full-time students while the majority of local students were enrolled part-time. Further, $39 \%$ of the students in the sample were female and $61 \%$ were male. The majority of students $(56 \%)$ were between 25 and 30 years of age, while the next significant age range group was 31-40 years (17\%). A comparison of the sample with the demographics of the postgraduate students showed that the sample closely resembles the population of postgraduate students studying at the university.

\section{Analysis of the server data}

The web data retrieved from the server were analysed to investigate general usage pattern. Figure 2 presents a comparison of the login data on a weekly basis. The percentage of login data per week is calculated by dividing the number of logins during the week to the total number of logins through the semester.

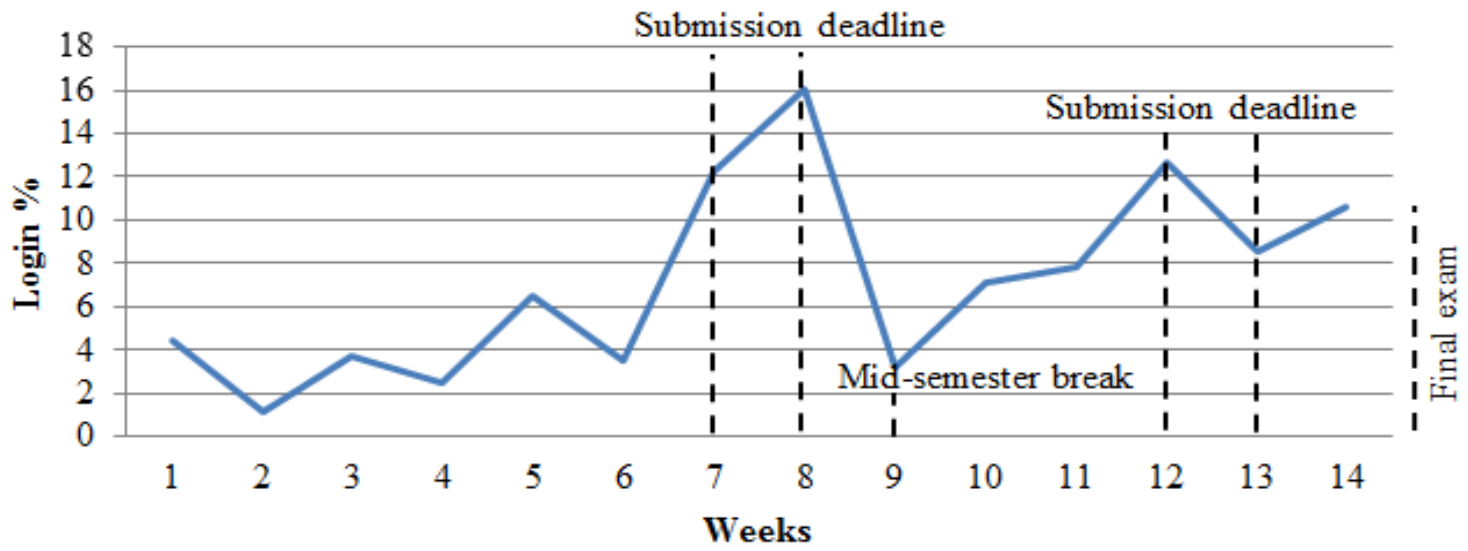

Figure 2. Comparison of the login data by week

In analysing the data in Figure 2, the following matters were considered: (1) a standard teaching semester at the university is 12 weeks but the results were collected for 14 weeks; and (2) the additional two weeks were one week during the mid-semester break and the week preceding the exam period when students were allowed to work on the wiki. The results in Figure 2 show a slight decrease in usage in week 6 associated with a submission deadline on another subject in which students were enrolled. A sudden drop in online usage in week 9 can be explained by a mid-semester break. The online data show two peak times of wiki usage in weeks $7-8$ (12.2\% and 16.1\%) and weeks $12-14(12.7 \%, 8.5 \%$ and $10.6 \%)$. These times coincided with deadlines for assessment submissions, indicating that wiki usage is strongly linked with assessment deadlines.

Further analysis of the web data shown in Table 1 (see Appendix A for descriptions of the variables) reveals that the average number of wiki pages created by each student was 13.83. Even though the 
students were encouraged to collaborate on a shared wiki page in a group, students preferred to work on separate pages and link them later. In most cases, these pages were revised later (minor edits $=6.77$ and major edits $=21.12$ ). This shows that students were motivated to go back to their work and amend it as they progressed through the course. Students reviewed pages created by other group members, but were reluctant to edit them (major edits $=4.14$ and minor edits $=6.05$ ). The results show that students interacted with other group members via comments, receiving an average of 6.09 comments and leaving an average of 6 comments. Students created a hierarchy of links, adding links to pages of other group members (mean=6.92) and allowing links to their own pages (mean=5.22).

Table 1

Basic statistics of major learning behaviour variables

\begin{tabular}{lrrr}
\hline Variable name & $N$ & Mean & $S D$ \\
\hline BytesContributedExternal (000) & 83 & 688.42 & 355.29 \\
BytesContributedOwn (000) & 83 & 5514.00 & 3154.86 \\
CommentsLeft & 83 & 6.00 & 3.09 \\
CommentsReceived & 83 & 6.09 & 3.19 \\
InternalLinks & 83 & 5.22 & 2.63 \\
MajorEditsExternal & 83 & 4.14 & 1.93 \\
MajorEditsOwn & 83 & 21.12 & 11.95 \\
MediaExternal & 83 & .54 & .50 \\
MediaOwn & 83 & 4.18 & 2.42 \\
MinorEditsExternal & 83 & 6.05 & 2.46 \\
MinorEditsOwn & 83 & 6.77 & 3.68 \\
Pages & 83 & 13.83 & 7.78 \\
RelatedPages & 83 & 6.92 & 3.38 \\
ViewsExternal & 83 & 8.72 & 4.42 \\
ViewsOwn & 83 & 47.27 & 26.49 \\
\hline
\end{tabular}

To describe variability among the observed variables and calculate the factor structure, principal component analysis (PCA) with orthogonal rotation (varimax) was applied. PCA is used to reduce the dimensionality of a data while retaining as much as possible the variation present in the data set (Kline, 1999).

During the PCA, great care was taken to ensure that the eigenvalues of the factors would be at least 1 (Shevlin \& Lewis, 1999) and that the value of the factor loading would be at least 0.5 (Hutchenson \& Sofroniou, 1999). For factorability of the data, the Kaiser Mayer Olkin (KMO) measure of sampling adequacy and the Bartlett test were used. The KMO measure verified the sampling adequacy for the analysis, $\mathrm{KMO}=925$. All $\mathrm{KMO}$ values for individual items were $>0.88$, which is well above the acceptable limit of 0.5 . Bartlett's test of sphericity $\chi^{2}(105)=2750.177, p<0.001$, indicated that correlations between items were sufficiently large for PCA. An initial analysis was run to obtain eigenvalues for each component in the data. Two components had eigenvalues over Kaiser's criterion of 1. The PCA concluded that the set of interactions had a two-factor structure accounting for $75 \%$ of the total variance (RQ1). Table 2 shows the factor loading after rotation. 
Table 2

Factors and their component variables

\begin{tabular}{lcc}
\hline Variable name & $\begin{array}{l}\text { Student-student } \\
\text { Panel A }\end{array}$ & $\begin{array}{l}\text { Student-content } \\
\text { Panel B }\end{array}$ \\
\hline BytesContributedExternal & .946 & .961 \\
BytesContributedOwn & .921 & \\
CommentsLeft & .899 & \\
CommentsReceived & .905 & \\
InternalLinks & .847 & .961 \\
MajorEditsExternal & & .950 \\
MajorEditsOwn & .821 & \\
MediaExternal & & .933 \\
MediaOwn & .884 & .948 \\
MinorEditsExternal & & .947 \\
MinorEditsOwn & & \\
Pages & .909 & \\
RelatedPages & .950 & \\
ViewsExternal & & \\
ViewsOwn & & \\
\hline
\end{tabular}

One of these factors consisted of nine items (see Table 2 Panel A). Factor loading of the items included in this factor ranged between 0.821 and 0.950 . The items that loaded heavily on this factor included ViewsExternal (factor loading of 0.950), BytesContributedExternal (factor loading of 0.946) and CommentsLeft (factor loading of 0.921). Careful examination of items included in the factor showed that all items exhibit a degree of interaction with other users as defined by Moore (1989):

- $\quad$ items BytesContributedExternal, MinorEditsExternal and MajorEditsExternal measure editing on pages created by other users;

- $\quad$ items CommentsReceived and CommentsLeft measure comments received/left for other users;

- $\quad$ items InternalLinks and RelatedPages reflect integration with pages created by other users;

- items viewsExternal and MediaExternal include an active knowledge sharing/exchange component with other users.

All nine items had a shared conceptual meaning and measured the construct that matched "student-student interaction" in Moore's taxonomy (1989), thus this factor was termed "student-student interaction" (Table 2 Panel A).

The second factor consisted of six items. Factor loading of the items included in this factor ranged between 0.933 and 0.961. Items such as MajorEditsOwn (factor loading of 0.961), BytesContributedOwn (factor loading of 0.961) and MediaOwn (factor loading of 0.950) were items that loaded heavily on this factor. Careful examination of the items suggested that all six items shared the same construct, which is various types of edits of the content owned by the user, and referred to personal construction of knowledge in Moore's taxonomy (1989). This factor was termed "student-content interaction" (Table 2 Panel B).

To assess the internal reliability for the interaction scale the study employed the Cronbach's alpha. The estimates were 0.82 (Student-content interaction construct) and 0.81 (Student-student interaction construct). These values are considered acceptable for measures in the social science (Kline, 1999). 
Further, a cluster analysis was employed to understand the possible grouping of the identified factors within online behaviour patterns to address $R Q 2$. To ensure the accuracy of the clusters and determine the optimal number of clusters, we employed the hierarchical cluster analysis and the Ward method's dendrogram. With the aid of a dendrogram derived from the data, participants were categorised into three groups. The cluster analysis with the option to group by means of the k-averages method was employed. To confirm the validity of the groupings, Kruskal-Wallis tests were conducted on all variables. The results of the grouping are shown in Table 3 .

Table 3

Cluster characteristics

\begin{tabular}{lccc}
\hline Variable name & $\begin{array}{l}\text { Lower } \\
\text { performance } \\
\text { cluster } \\
(N=23)\end{array}$ & $\begin{array}{l}\text { Moderate } \\
\text { performance } \\
\text { cluster } \\
(N=39)\end{array}$ & $\begin{array}{l}\text { Higher } \\
\text { performance } \\
\text { cluster } \\
(N=21)\end{array}$ \\
\hline Panel A & nov.70 & 776.08 & 848.46 \\
BytesContributedExternal (000) & 3 & 7 & 8 \\
CommentsLeft & 3 & 7 & 7 \\
CommentsReceived & 3 & 6 & 7 \\
InternalLinks & 3 & 5 & 5 \\
MajorEditsExternal & 0.30 & 0.58 & 0.71 \\
MediaExternal & 4 & 7 & 7 \\
MinorEditsExternal & 4 & 8 & 9 \\
RelatedPages & 5 & 10 & 11 \\
ViewsExternal & & & \\
& 1251.60 & 5766.39 & 9724.10 \\
Panel B & 5 & 22 & 37 \\
BytesContributedOwn $(000)$ & 0.96 & 4.39 & 7.33 \\
MajorEditsOwn & 2 & 7 & 11 \\
MediaOwn & 3 & 15 & 24 \\
MinorEditsOwn & 12 & 50 & 81 \\
Pages & & & \\
ViewsOwn & & & \\
\hline & & & \\
\hline
\end{tabular}

The first cluster included 23 students $(n=23 ; 27.71 \%)$ and was labelled "lower performance". Students in this cluster were characterised by low online participation, including lowest number of created pages, views and edits of their own pages and pages created by others. Interaction with other students was very limited which was reflected in low exchange of comments and undeveloped linkages structures. The second cluster included the highest number of students $(n=39 ; 46.99 \%)$. They showed average level of online activity as measured by the variables. The cluster was labelled "moderate performance". The last cluster $(n=21 ; 25.30 \%)$ was characterised by high online activity level, including highest number of created pages, views and edits of owned pages. However, interaction with other students (external edits/views, comments exchange, links structure) did not differ significantly from the pattern exhibited by the "moderate performance" students. Compared to moderate performing students, higher performing students concentrated on building up the content, rather than engaging in more collaboration with other students. 
To confirm this finding and analyse the distinctive features of the clusters further, the study employed comparison of cluster means across the two factors identified via the PCA. Based on the factors' loading, two composite variables were calculated using the Anderson-Rubin method to ensure that the factors are uncorrelated. Due to the relatively small sample size, a nonparametric approach was employed. The Kruskal-Wallis test confirmed the behaviour of the factors differed across clusters. The clusters differed significantly on the level of student-content interaction, $\mathrm{H}(2)=69.17, p<.01$, and less significantly on the level of student-student interaction, $\mathrm{H}(2)=7.19, p<.05$. Jonckheere's test showed a significant trend in the data: the more active online participation is associated with higher student-content interaction, $\mathrm{J}=6, z=-$ 9.27, $r=-1.02$, rather than student-student collaboration. While "lower performance" students tried to comply with the wiki assignment requirement of collaboration, "higher performance" students tended to work in their "cells" rather than collaborate online with other students in an increased manner.

\section{Analysis of interviews}

As suggested by the prior literature (Zorko, 2009; Naismith et al., 2011) it was decided to extend the analysis of online server logs to include offline interaction investigation. The second stage of the research involved interviews with students. The data obtained at the first stage related to student performance online, while the interviews were expected to extend the findings further by investigating the offline aspect of the wiki project and address RQ3.

Students from each cluster identified in the first stage of the research were invited to participate in an interview to obtain further insight into their group activities. The interviews were conducted online using Google Talk software to facilitate participation of international students offshore. The interviews were undertaken after the release of final grades for the subject. Ten students agreed to participate (four female and six male). Of the 10 respondents, only one had studied in the previous five years. Due to the nature of the postgraduate degree, it is expected that students enrolled in the degree have a solid work experience, thus, such pattern in their educational experience was anticipated. Further analysis showed that since the unit of study does not have prerequisites, the majority of students undertake it in the first semester of their postgraduate study. Thus, the characteristics of our sample of interviewees match the population of students in this unit of study.

Table 4 presents details and demographic information about the interviewees. Quotations from each respondent included in the paper are identified using the Student's number as shown in Table 4. According to Guest, Bunce, and Johnson (2006), this sample size was adequate as basic elements for meta themes are generally present as early as six interviews.

Table 4

Profile of respondents

\begin{tabular}{lllllll}
\hline $\begin{array}{l}\text { Student } \\
\text { No. }\end{array}$ & Age & Gender & $\begin{array}{l}\text { International } / \\
\text { Domestic }\end{array}$ & $\begin{array}{l}\text { Enrolment } \\
\text { status }\end{array}$ & $\begin{array}{l}\text { Level of IT skills } \\
\text { (self-assessed) }\end{array}$ & $\begin{array}{l}\text { Use of } \\
\text { wiki }\end{array}$ \\
\hline 1 & 43 & Female & Domestic & Part-time & Moderate & High \\
2 & 47 & Male & Domestic & Full-time & Low & Low \\
3 & 35 & Male & Domestic & Part-time & Moderate & Low \\
4 & 28 & Male & International & Full-time & High & High \\
5 & 29 & Male & International & Full-time & High & Moderate \\
6 & 27 & Male & International & Full-time & Moderate & Moderate \\
7 & 28 & Female & International & Full-time & Moderate & Moderate \\
8 & 27 & Male & International & Full-time & Moderate & Moderate \\
9 & 23 & Female & Domestic & Part-time & Low & Low \\
10 & 28 & Female & International & Full-time & Moderate & Low \\
\hline
\end{tabular}


The semi-structured interviews were conducted using nondirective and reflective techniques via open questioning and encouraging corroborating and expanding responses. Order and phrasing of questions were sufficiently flexible to allow variation if necessary. The interviews were structured around potentially influential experiential areas that were identified from prior research outlined in the literature review by Johnson \& Johnson (2000), Wheeler et al. (2008), Pieterse \& Thompson (2010) and Snodgrass (2011).

The preliminary structuring allowed several categories to develop. Data was analysed further using open coding techniques to establish the emergent themes. The analysis of the transcripts proceeded over a number of iterations to enhance understanding. The coded data were cross-checked to ensure the validity and reliability of data interpretation.

Initially, students were asked to reflect on online/offline collaboration, comment on the level of their interaction and factors that affected it. The initial findings about interaction during the project (RQ1) were subsequently explored at a deeper level to allow comparison among cluster of users (RQ2) and to draw a list of possible explanatory factors (RQ3). The analysis of the interview scripts enabled us to identify the following themes:

Theme 1: Level of IT skills

All students who participated in the interviews indicated that they had previous experience with IT either at work or in their previous studies. However, the level of their IT skills varied (Table 4). Interestingly, none of the students from the "low performance" cluster had high IT skills. Further, none of the "high performance" interviewees indicated low IT skills. Two interviewees from the "low performance" cluster with low IT skills experienced technical difficulties working with wiki:

I am not an IT person and it was difficult for me to work with the wiki at first'(Student 2).

As suggested by Neumann and Hood (2009) and Guo and Stevens (2011), there is a dependency between prior experience with IT/wiki and level of wiki usage. Our results support this finding and extend it further by suggesting a stronger correlation between a level of IT skills and a level of student-student interaction (Panel A). While students with low IT skills tend to cope with the student-content interaction component (Panel B), they find student-student interaction (Panel A) to be challenging. Notably, students from the "low performance" cluster (with low and moderate level of IT skills) were more inclined to perceive collaboration options in wiki as rigid and the wiki interface as not user friendly:

I was fine with creating pages and putting text there, but it was difficult for me to insert images, video or links (Student 10).

I was afraid to edit pages created by other group members as I was afraid that I can accidentally delete something there or remove the whole page (Student 2).

Students from two other clusters also indicated that from the technical point, student-student interaction (Panel A) required more advanced IT skills. Students who were less advanced in IT, preferred to work on their own pages, rather than to contribute/comment to pages created by others:

I was not confident in the technical side, so first I preferred my group mates to set up links to my pages (Student 6).

It was easier for me to work on my own pages, because I am not that technical (Student 9).

Leaving comments on other students' pages was easy, but I did not want to mess with inserting images or video on those pages. I did not want to screw up other people's work (Student 10).

Theme 2: Assignment related

Prior studies (Hathorn \& Ingram, 2002) indicate that assignment tasks can affect student collaboration. Increased workloads around submission deadlines (Figure 2) and interviews with students confirmed this finding and allowed further exploration in relation to student-student and student-content interaction. 
Students noted that individual work dominated in the wiki project and despite its collaborative nature, this assignment was regarded more as an individual, rather than group assessment. When asked to elaborate on this perception further, students brought up the following consideration:

Task structure:

Respondents commented that collaboration prevailed where mini-tasks were structured in a way that allowed only one student at a time to make changes to the text. Thus, each student was required to read the text entered by the previous user and continue it by integrating his/her knowledge. This finding is in line with Wichmann and Rummel (2013) who argue that a linear text structure promotes collaboration.

Amount and regularity of mini-tasks:

Respondents stated that even though the assignment task itself was collaborative in nature, some students felt overwhelmed that they were asked to contribute to the wiki at each tutorial, while others stated that it created an opportunity to stay on track with the task and collaborate with their group mates on a regular basis. Interestingly, the first type of comments was received from students from lower and moderate performance clusters, while the second type of comments were from higher performance students.

Timing of the allocated tutorial:

Students commented that allocating time to work on the wiki during the tutorial encouraged collaboration with other students; however, if students were unable to attend, they felt it was difficult to get back with their group:

I could not attend the majority of tutorials due to my work commitments, so I felt missed out (Student 9).

Also, some students commented that 20 minutes per class was not enough and suggested extending this time to 30 minutes, to allow time to discuss ideas within a group and start work on individual sections in a class:

Every time it took me ten minutes to login to wiki because I forgot my password and had to reset it. I did not have time to work with my group and do anything on wiki during tutorials (Student 2).

Theme 3: Organisation of group work

Even though students were provided with guidelines on effective collaboration at the beginning of the semester, the choice of strategies for collaboration was left with individual groups. As it was found from server logs (Table 1) and PCA (Table 2), the majority of students preferred to work on individual wiki pages and link them later into a structure of links. When asked to elaborate on this aspect of their group work, the following comments were received indicating that additional work was required to organise collaboration on shared pages:

Working on the same page was not time effective. Ideally, we will have to wait for a group member to finish his/her job and only then we can start contributing (Student 4).

I did not feel that working on the same page is fair because somebody has to do the bulk [of the] writing and then one has to make sure that everybody will contribute to the page (Student 8).

Apart from comments dealing with purely organisation issues of group work, some comments related to personal traits:

I am not comfortable [to] just go and edit somebody's work. I would rather express my opinion and ask that person to edit their work (Student 1). 
Also, some technical issues were brought up during the interview:

If you have the link that you want to comment on, it is all fine. But it can be quite tricky to use the search option in the wiki. The system is case sensitive so if you search for the same word with a small letter and the user created it with a capital letter, it will not show up (Student 8).

Wiki is quite rigid. There was a small miscommunication and we ended up with two sets of pages on the same question for the mini task, because it allowed up to create two pages with the same name, but spelt differently (Student 6).

To stimulate collaboration (as opposed to cooperation), students were encouraged to start peer reviewing pages early in the semester. However, several interviewees expressed a mixed opinion on this approach:

Receiving comments early in the work was good, but sometimes people commented just to boost their comments count (Student 4).

Finally, the majority of the respondents (seven out of 10) mentioned that having other group activities in the course was very helpful for the online project:

We had an opportunity to work as a group with the same people and that made things much easier because we know what to expect from each other (Student 7).

Theme 4: Availability of alternative means of interaction

Interviewees indicated that having too many options for interaction (wiki, e-mail, chats, forum, etc.) was confusing as they perceived that their collaborative effort was dispersed. This extends the previous finding of Zorko (2009) that students preferred to use alternative software that allowed immediate contact with peers:

For other assignments, we used emails and skype to communicate. Since we did all assignments with the same people, it would be easier for us to discuss all assignments in the same email, not to go to the wiki and write there (Student 6).

In the wiki I had to make sure that the system has my records, otherwise I could lose marks (Student 5).

Theme 5: Role of instructor

Instructors' opinions are very important in forming students' attitudes toward technologies (Guo \& Stevens, 2011). Student-instructor interaction is also an integral part of the educational interactions scheme. The results of the interviews showed that the role of the instructor is particularly important for encouraging student-student interaction, though it also facilitates student-content interaction.

I liked it when our tutor showed us how to leave comments and reply to them. She made it fun (Student 7).

I was not familiar with wiki and it was good that I could ask my tutor for help (Student 2).

Wiki is very rigid, but I enjoyed how our tutor motivated us to use it (Student 1).

\section{Implications and conclusion}

\section{Implications for research}

This study has a number of important contributions to the existing literature on collaborative learning and online interaction.

First, the study follows a call from Gredler (2005) to address different types of interactions for various uses of computer technology and investigates interaction in a wiki-based collaborative project in a 
blended learning environment. Furthermore, the study extends the framework suggested by Trentin (2009) by investigating the interaction component of online collaboration.

Second, the study identifies the cluster of users based on their online interaction pattern and investigates specific features of those users. It sheds light on prior findings by Judd et al. (2010) and Naismith et al. (2011) of ineffective collaboration in wikis by investigating a balance between student-student vs studentcontent collaboration in three clusters with different online activity levels.

Third, the results of the study extend prior literature on factors that affect online wiki participation. Prior research (Neumann \& Hood, 2009; Guo \& Stevens, 2011) indicates that prior experience with IT/wiki affects wiki usage, and the present study found a more accurate relation. In our findings, prior experience with IT/wiki is particularly important for student-student interaction and not that important for studentcontent interaction. Further, the role of the instructor is vital for wiki collaboration (Guo \& Stevens, 2011); the results of the present study indicate that it affects student-content interaction and is particularly important for stimulating student-student interaction.

\section{Implications for practice}

The current study has a number of contributions to practice. The following guidelines can be used to encourage different types of interactions in wiki-based collaborative projects.

- The level of use of the wikis is influenced by the students' level of experience and expertise with wikis (Guo \& Stevens, 2011). Students with low IT skills/prior experience with wiki will benefit from an additional workshop on interactive capacities of wiki (e.g., using shared pages in wiki, inserting links, development of a structure of links) to increase student-student interaction.

- When planning a wiki assignment, the instructor should take special care to discourage cooperation and promote collaboration (Naismith et al., 2011). A shorter mini-task may be more beneficial for this purpose. Collaboration can also be promoted through the task structure that allows only one user at a time to enter text.

- Allocation of sufficient time during the tutorial gives students an opportunity to collaborate and promote student-student interaction.

- Linear text structure promotes collaboration (Wichmann \& Rummel, 2013). Working on shared wiki pages increases student-student interaction, thus students should be encouraged to use shared pages for shorter tasks.

- Peer review should be encouraged early in the wiki project. However, a mechanism should be put in place to ensure its quality (e.g., wiki protocol developed by students themselves).

- Using wiki together with other group activities encourage student-student collaboration.

- In line with Zorko (2009), care should be taken as not to introduce too many channels of communication (e.g., wiki, emails, forums, chat).

- Extending the finding of Guo and Stevens (2011), the role of the instructor is particularly important in encouraging student-student interaction.

\section{Conclusion}

Prior literature shows that interaction in wiki-based collaboration projects may not be effective (Judd et al., 2010; Naismith et al., 2011). This study explored the interaction area further to understand which particular aspect of interaction requires improvement. It reported on the types of online interactions in which students were involved, interaction patterns that were observed among clusters of students and factors that affected those patterns of interaction. Analysis of the server logs showed that students' interactions online were of two types, student-content and student-student, with student-content interaction being dominant. Further investigation of patterns of students' behaviour online allowed identification of three clusters - lower performance, moderate performance and higher performance. The lower performance cluster was characterised by low student-student as well as low student-content interaction. The moderate and higher performance clusters differed on the level of student-content interaction (it was higher for the higher performance cluster). The level of student-student interaction was the same. This finding suggests that higher performance students did not want to extend their 
collaboration with other students and preferred to work in their "cells." Further interviews with students allowed the findings to be extended and the identification of factors that affect interaction:

IT skills/wiki experience:

Confirming the previous finding of importance of IT skills and prior experience with wiki (Neumann \& Hood, 2009; Guo \& Stevens, 2011), the results showed that compared to student-content interaction, student-student interaction required a higher level of IT experience.

Assignment related:

Hathorn and Ingram (2002) suggest that assignment tasks can affect student collaboration. The results confirmed that shorter tasks assigned to student groups on a regular basis discouraged cooperation and encouraged collaboration. Allocation of time during tutorials not only encouraged collaboration in class, but also encouraged student-student interaction online.

Organisation of group work:

Working on shared wiki pages may encourage student-student interaction, but it required additional work on organising collaboration in a group. However, some students may not feel comfortable to "intrude" into other students' work. Peer review stimulates collaboration (Snodgrass, 2011). Encouraging students to start peer reviewing early in the semester stimulated student-student collaboration. However, a mechanism should be put in place to ensure that the quality of the feedback is maintained. Finally, the combination of a wiki project with face-to-face forms of group activities enhanced some students' learning experience as students felt more comfortable and developed a deeper sense of community.

Availability of alternative means of interaction:

Availability of alternative means of interaction was confusing since students perceived that their interaction effort was dispersed.

Role of instructor:

The attitude of the instructor influences a students' perception towards wikis (Guo \& Stevens, 2011). The instructor's opinion is particularly important for encouraging student-student interaction.

With rapid development of wiki use in education, further research on the interaction component of collaborative projects is required. Possible directions include investigation of dynamics of students' interactions and further integration of the present approach into a comprehensive framework for evaluation of wiki-based projects, including the assessment of learning outcomes and skills formation.

\section{References}

Anderson, T. (2008). Toward a theory of online learning. In T. Anderson (Ed.), Theory and Practice of Online Learning. Edmonton: Athabasca University.

Bower, M., Woo, K., Roberts, M. \& Watters, P. (2006). Wiki pedagogy - a tale of two wikis. In The Information Technology Based Higher Education and Training Conference. Proceedings Sydney 2006, 191-202.

Bryant, S. M., \& Albring, S. M. (2006). Effective team building: Guidance for accounting educators. Issues in Accounting Education, 21(3), 241- 265.

Carlson, R. D., \& Reepman, J. (1999). Web-based interactivity. Web Net Journal, 1(2), 11-13.

Choy S. O., \& Ng, K. (2007). Implementing wiki software for supplementing online learning. Australasian Journal of Educational Technology, 23(2), 209-226.

Creswell, J. W. (1998). Qualitative inquiry and research design: Choosing among five traditions. Thousand Oaks: Sage.

Donnelly, R. (2010). Harmonizing technology with interaction in blended problem-based learning. Computers \& Education, 54(2), 350-359. 
Elgort, I., Smith, A.G., \& Toland, J. (2008). Is wiki an effective platform for group course work? Australasian Journal of Educational Technology, 24(2), 195-210.

Gredler, M. E. (2005). Learning and instruction: Theory into practice (5th ed.). Upper Saddle River: Pearson Education.

Green, H., \& Hannon, C. (2007). Their space: Education for a digital generation. London: Demos.

Guest, G., Bunce, A., \& Johnson, L. (2006). How many interviews are enough? An experiment with data saturation and variability. Field Methods, 18(1), 59-82.

Guo, Z., \& Stevens, K. J. (2011). Factors influencing perceived usefulness of wikis for group collaborative learning by first year students. Australasian Journal of Educational Technology, 27(2), 221-242.

Hathorn, L. G., \& Ingram, A. L. (2002). Online collaboration: Making it work. Educational Technology, $42(1), 33-40$.

Hirumi, A. (2002). The design and sequencing of e-learning interactions: a grounded approach. International Journal on E-Learning, 1(1), 19-27.

Hutchenson, G., \& Sofroniou, N. (1999). The multivariate social scientist. London: Sage.

Johnson, D. W., \& Johnson, R. (2000). Joining together: Group theory and group skills (7th ed.). Needham Heights: Pearson Education.

Johnson, D. W., Johnson, R. T., \& Holubec, E. J. (1984). Cooperation in the classroom. Edina: Interaction Book Co.

Judd, T., Kennedy, G., \& Cropper, S. (2010). Using wikis for collaborative learning: Assessing collaboration through contribution, Australasian Journal of Educational Technology, 26(3), 341-354.

Kagan, S. (1989). Cooperative learning resources for teachers. San Juan Capistrano: Resources for Teachers.

Kear, K., Woodthorpe, J., Robertson, S. \& Hutchison, M. (2010). From forums to wikis: Perspectives on tools for collaboration. The Internet and Higher Education, 13(1), 218-225.

Kline, P. (1999). The handbook of psychological testing (2nd ed.). London: Routledge.

Lee, S. W.-Y., \& Tsai, C.-C. (2011). Identifying patterns of collaborative knowledge exploration in online asynchronous discussions. Instructional Science, 39, 321-347.

Lundin, R. W. (2008). Teaching with wikis: Toward a networked pedagogy. Computers and Composition, 25(4), 432-448.

Michinov, N. \& Michinov, E. (2008). Face-to-face contact at the midpoint of an online collaboration: Its impact on the patterns of participation, interaction, affect, and behavior over time, Computers \& Education, 50(4), 1540-1557.

Moore, M. (1989). Three types of interaction. The American Journal of Distance Education, 3(2), 1-7.

Moskaliuk, J., Kimmerle, J., \& Cress, U. (2012). Collaborative knowledge building with wikis: The impact of redundancy and polarity. Computers \& Education, 58(4), 1049-1057.

Naismith, L., Lee, B.-H., \& Pilkington, R. M. (2011). Collaborative learning with a wiki: Differences in perceived usefulness in two contexts of use. Journal of Computer Assisted Learning, 27(3), 1-15. 
Neumann, D. L., \& Hood, M. (2009). The effects of using a wiki on student engagement and learning of report writing skills in a university statistics course. Australasian Journal of Educational Technology, $25(3), 382-398$

O'Reilly, T. (2007). What is Web 2.0: Design patterns and business models for the next generation of software. International Journal of Digital Economics, 65(1), 17-37.

Oliveira, I., Tinoca, L., \& Pereira, A. (2011). Online group work patterns: How to promote a successful collaboration. Computers \& Education, 57(1), 1348-1357.

Pieterse, V., \& Thompson, L. (2010), Academic alignment to reduce the presence of 'social loafers' and 'diligent isolates' in student teams. Assessment \& Evaluation in Higher Education, 15(4), 355-367.

Redecker, C. (2009). Review of learning 2.0 practice: Study on the impact of Web 2.0 innovations in education and training in Europe. Seville: European Commission Joint Research Centre Institute for Prospective Technological Studies.

Richardson, W. (2006). Blogs, wikis, podcasts, and other powerful web tools for classrooms. Thousand Oaks: Corwin Press.

Roschelle, J., \& Teasley, S. D. (1995). The construction of shared knowledge in collaborative problem solving. In C. E. O'Malley (Ed.), Computer Supported Collaborative Learning. Heidelberg: Springer.

Shevlin, M. E., \& Lewis, C. A. (1999). The revised social anxiety scale: exploratory and confirmatory factor analysis. The Journal of Social Psychology, 139(2), 250-252.

Sims, R. (2003). Promises of interactivity: aligning learner perceptions and expectations. Distance Education, 24(1), 87-103.

Snodgrass, S. (2011). Wiki activities in blended learning for health professional students: Enhancing critical thinking and clinical reasoning skills. Australasian Journal of Educational Technology, 27(4), 563-580.

Stahl, G., Koschmann, T., \& Suthers, D. (2006). Computer-supported collaborative learning: An historical perspective. In R. K. Sawyer (Ed.), Cambridge Handbook of the Learning Sciences. Cambridge: Cambridge University Press.

Ting, Y.-L. (2013). Using mobile technologies to create interwoven learning interactions: An intuitive design and its evaluation. Computers \& Education, 60(1), 1-13.

Trentin, G. (2009). Using a wiki to evaluate individual contribution to a collaborative learning project. Journal of Computer Assisted Learning, 25(1), 43-55.

Vratulisa, V., \& Dobsona, T. M. (2008). Social negotiations in a wiki environment: A case study with pre-service teachers. Educational Media International, 45(4), 285-294.

Wagner, E. (2005). Interaction strategies and experience design: Guidelines for technology-mediated learning. In P. Kommers \& G. Richards (Eds.), Proceedings of the World Conference on Educational Multimedia, Hypermedia and Telecommunications 2005, (pp. 4118-4119). Chesapeake, VA: AACE.

Wagner, E. D. (2006). On designing interaction experiences for the next generation of blended learning. In C. J. Bonk \& C. R. Graham (Eds.), The handbook of blended learning. Global perspectives, local designs. San Francisco: Pfeiffer.

Wheeler, S., Yeomans, P., \& Wheeler, D. (2008). The good, the bad and the wiki: Evaluating studentgenerated content for collaborative learning. British Journal of Educational Technology, 39(6), 987995. 
Wichmann, A., \& Rummel, N. (2013). Improving revision in wiki-based writing: Coordination pays off. Computers \& Education, 62, 262-270.

Yun, K. (2005). Collaboration in the semantic grid: a basis for e-learning. Applied Artificial Intelligence, $19(9 \& 10), 881-904$.

Zorko, V. (2009). Factors affecting the way students collaborate in a wiki for English language learning. Australasian Journal of Educational Technology, 25(5), 645-665.

Corresponding author: Maria Prokofieva, maria.prokofieva@vu.edu.au

Australasian Journal of Educational Technology (C) 2013.

Please cite as: Prokofieva, M. (2013). Evaluating types of students' interactions in a wiki-based collaborative learning project. Australasian Journal of Educational Technology, 29(4), 496-512.

\section{Appendix A}

Table A

Log file variables

\begin{tabular}{|c|c|}
\hline Variable & Description \\
\hline BytesContributedExternal & $\begin{array}{l}\text { Quantitative measure of user's contributions on pages created by other } \\
\text { users }\end{array}$ \\
\hline BytesContributedOwn & $\begin{array}{l}\text { Quantitative measure of user's contributions on pages created by this } \\
\text { user }\end{array}$ \\
\hline CommentsLeft & Number of comments left by this user on pages created by other users \\
\hline CommentsReceived & Number of comments left by other users on pages created by this user \\
\hline ID & User ID \\
\hline InternalLinks & Number of links to pages created by other users (set up by the user) \\
\hline MajorEditsExternal & $\begin{array}{l}\text { Total number of major edits ( } \geq 25 \% \text { of the original page) on pages } \\
\text { created by other users }\end{array}$ \\
\hline MajorEditsOwn & $\begin{array}{l}\text { Total number of own major ( } \geq 25 \% \text { of the original page) edits on pages } \\
\text { created by this user }\end{array}$ \\
\hline MediaExternal & $\begin{array}{l}\text { Total number of media (images, video, files) uploads on pages created } \\
\text { by other users }\end{array}$ \\
\hline MediaOwn & $\begin{array}{l}\text { Total number of media (images, video, files) uploads on pages created } \\
\text { by this user }\end{array}$ \\
\hline MinorEditsExternal & $\begin{array}{l}\text { Total number of minor edits ( }<25 \% \text { of the original page) on pages } \\
\text { created by other users }\end{array}$ \\
\hline MinorEditsOwn & $\begin{array}{l}\text { Total number of own minor ( }<25 \% \text { of the original page) edits on pages } \\
\text { created by this user }\end{array}$ \\
\hline Pages & Total number of created wiki pages \\
\hline RelatedPages & $\begin{array}{l}\text { Number of links that reference pages created by the user (set up by other } \\
\text { users) }\end{array}$ \\
\hline ViewsOwn & Number of views by external users of all pages created by this user \\
\hline ViewsExternal & Number of times this user viewed pages created by other users \\
\hline
\end{tabular}

